\title{
Diálogos sobre lo informe: Trayectoria de Bataille a Poeta en Nueva York ${ }^{*}$
}

\author{
Dialogues on the formless: Trajectory from \\ Bataille to Poeta en Nueva York
}

\begin{abstract}
DAVID F. RiCHTER
Utah State University. Logan, UT, Estados Unidos

david.richter@usu.edu

\section{RESUMEN}

Este trabajo investiga las variaciones del surrealismo español tomando como modelo de anclaje la contingencia intelectual del pensador francés Georges Bataille, y así ofrece una nueva lectura del poemario lorquiano Poeta en Nueva York. Los conceptos batailleanos de lo informe y el materialismo bajo subrayan una estética surrealista disidente que considera la angustia del sujeto poético y los viles instintos de la realidad. En la obra de Lorca la representación del ente fragmentado y decaído demuestra una preocupación surrealista humanizada que rompe con las postulaciones del automatismo del pensador "oficial" del surrealismo, André Breton.
\end{abstract}

Palabras clave: Federico García Lorca, Poeta en Nueva York, Georges Bataille, Documents, surrealismo.

\section{ABSTRACT}

This article examines variations of Spanish surrealism taking into account the intellectual contributions of the French thinker Georges Bataille, thus offering a new reading of Federico García Lorca’s poetic collection Poeta en Nueva York. The Bataillean concepts of "the formless" and base materialism underscore a dissident

"Agradezco los valiosos comentarios y sugerencias de los siguientes colegas: Gregory Stallings, Christina Karageorgou-Bastea, Esther Fernández, Christopher Maurer y Javier Domínguez-García. Asimismo, agradezco las excelentes sugerencias de los evaluadores de Acta Literaria. 
surrealist aesthetic that considers the anguish of the poetic subject and the lowly instincts of reality. In Lorca's work, the representation of the fragmented and fallen subject demonstrates a humanized surrealist preoccupation that breaks with the principle of automatic writing affirmed by the "official" theorist of surrealism, André Breton.

Keywords: Federico García Lorca, Poeta en Nueva York, Georges Bataille, Documents, surrealism.

Recibido: 10.12.2012. Aceptado: 14.03.2013.

Y hoy no tengo más espectáculo que una poesía amarga, pero viva, que creo podrá abrir sus ojos a fuerza de latigazos que yo le dé (...) Arista y ritmo, forma y angustia, se los va tragando el cielo (García Lorca, 1996-1997: 163, 172).

C1 l espacio que el intelectual francés Georges Bataille ocupa dentro del campo adscrito a las teorías críticas y estéticas de la vanguardia europea es provocativo aunque poco estudiado. La revalorización de Bataille en las dos últimas décadas con respecto al arte moderno y postmoderno le ha consolidado primordialmente como un precursor de la filosofía deconstruccionista, aunque su inclusión en el conjunto de la producción crítica de la vanguardia española generalmente no se discute ${ }^{1}$. No obstante, cabe señalar que las propuestas de este francés excomulgado de la escuela surrealista bretoniana son muy parecidas a los modos de pensamiento y expresión de otros intelectuales de los años '20 y '30 en España. Juan Carlos Rodríguez, al referirse a algunos elementos surrealistas en la poesía de Federico García Lorca señala que

\footnotetext{
${ }^{1}$ En particular, podemos señalar los críticos de la revista estadounidense October como Rosalind Krauss, Yve-Alain Bois, Hal Foster y Denis Hollier. Además, la historiadora de arte Dawn Ades ha comentado de manera extensiva sobre Dalí y el surrealismo, acercando su lectura cada vez más a la estética batailleana. Una de las últimas contribuciones de Ades (2006, junto con Simon Baker) examina a fondo la revista disidente Documents que dirigió Bataille en 1929-1930. De interés para los hispanistas son los recientes libros Sacred Eroticism: Georges Bataille and Pierre Klossowski in the Latin American Erotic Novel de Juan Carlos Ubilluz (2006), el cual investiga la importancia de Bataille dentro del contexto de la literatura latinoamericana del siglo XX; y Jazz y literatura de Gregory Stallings (2009), el cual considera la estética batailleana al lado de la música jazz, la literatura hispánica y los estudios culturales postmodernos.
} 
la pasión por los ojos arrancados, por la redondez de los senos arrancados también, ya desde el "Martirio de Santa Olalla" hasta los poemas neoyorkinos, es algo que me recuerda directamente la Historia del ojo, de Bataille, el amor como transfiguración de la muerte, o de la relación entre la literatura y el mal. Hablar de Brecht, de Kafka o de Bataille no es gratuito: quizá sea la mejor manera de intentar clarificar por qué se puede considerar a Lorca un clásico moderno (Rodríguez, 2000: 173).

Es, pues, nuestro objetivo en este ensayo establecer un diálogo entre el pensamiento batailleano y las manifestaciones hispánicas de vanguardia, y en particular el surrealismo español, tomando como paradigma de trabajo el poemario lorquiano Poeta en Nueva York. Como metodología de análisis, consideramos que es necesario contextualizar las propuestas estéticas e ideológicas del intelectual francés para poder entender la relación, no sólo artística sino también dialéctica, que en este trabajo pretendemos demostrar que existe entre Bataille y la vanguardia hispánica. No aspiramos, sin embargo, a establecer un vínculo histórico ni coetáneo entre Bataille y los vanguardistas, sino más bien a explorar la manifestación intertextual que estos intelectuales comparten frente al fenómeno de la modernidad europea ${ }^{2}$.

El pensamiento batailleano busca asiduamente criticar y deconstruir los modelos de su época en cuanto al arte, la sociedad, la etnografía y la antropología. Su revista Documents sirvió en su momento como foro para los surrealistas de los años 1929 y 1930 que se encontraban decepcionados con la orientación de los movimientos estéticos de su tiempo. Los conceptos que en ella elaboró Bataille como editor sirvieron para desmontar y contrarrestar las representaciones sublimadas (o surreales) heredadas de las postulaciones teóricas de André Breton. Es precisamente en este diálogo con Breton cuando Bataille reconoce, desde un punto de vista existencialista, los

${ }^{2}$ Dicho esto, hay ciertos vínculos que sí podrían promover una lectura más historicista: en junio de 1922 Bataille estuvo en las celebraciones del Primer Concurso del Cante Jondo en Granada que Lorca ayudó a organizar; en mayo y junio de 1929 salieron noticias en La Gaceta Literaria de la publicación de la revista Documents en la que salieron muchas de las ideas estéticas y filosóficas de Bataille; por medio de Luis Buñuel y Salvador Dalí, los cuales sí tenían contacto con Bataille y otros en París, Lorca tenía otro acercamiento a las estéticas más recientes que emergían de Francia; otros vanguardistas españoles de la época hacían referencia a la importancia de la revista Documents, como José Moreno Villa en su "Poética" publicada en la antología de Gerardo Diego en 1932 (1998: 8-9; 2001: 629-32); y bien se sabe que Lorca era muy bien leído dentro de varios círculos vanguardistas y que, según Cernuda, "no tendría dificultad para sentir algo que estaba en el ambiente" (1957: 193). Lo que sí es cierto es que Bataille tuvo interés en la obra de Lorca. En 1946 publicó una traducción de la obra lorquiana Retablillo de don Cristóbal en su revista Actualité, número dedicado exclusivamente a "L'Espagne libre". 
bajos instintos que se manifiestan en la existencia humana y por ende en la producción artística de su época (como Historia del ojo, del año 1928). La principal base del desacuerdo entre Breton y Bataille resulta de la insistencia de Breton en que el surrealismo debe sublimar la experiencia humana hacia una realidad superior. En su primer manifiesto surrealista, Breton refleja este deseo cuando apuesta por "la futura armonización de estos dos estados, aparentemente tan contradictorios, que son el sueño y la realidad, en una especie de realidad absoluta, en una sobrerrealidad o surrealidad, si así se le puede llamar", o cuando afirma que "lo maravilloso es siempre bello, todo lo maravilloso, sea lo que fuere, es bello, e incluso debemos decir que solamente lo maravilloso es bello" (1969: 30-31). En la ilustración de estas postulaciones, Breton se refiere a los sueños puros à la Freud, las imágenes bellas, las visiones del amor, la libertad y a una realidad absoluta que deriva del automatismo psíquico puro (1969: 44), elemento definitorio del surrealismo para mucha de la crítica del siglo XX.

Los argumentos críticos que Bataille presenta en Documents articulan una mirada que rompe con lo que algunos han considerado el "idealismo bretoniano" (Foster, 2000: 229). En esta revista, que sólo duró poco más de un año, Bataille elabora su ataque al surrealismo ortodoxo en términos de lo informe, la abyección, el "materialismo bajo", el vacío y la putrefacción -valores "viles" que subvierten nociones idealistas de la identidad, la moral y la estética. Bataille expone su conceptualización de lo informe cuando matiza que

informe no es solamente un adjetivo con determinado sentido sino también un término que sirve para descalificar, exigiendo generalmente que cada cosa tenga su forma. Lo que designa carece de derecho propio en cualquier sentido y se deja aplastar en todas partes como una araña o una lombriz. Haría falta, en efecto - para que los académicos estén contentosque el universo cobre forma (...). En cambio, afirmar que el universo no se asemeja a nada y que sólo es informe significa que el universo es algo así como una araña o un escupitajo (2003: 55).

Mientras Breton ve la misión del surrealismo como un intento de ascender a una híper-realidad y una belleza exaltada o maravillosa, Bataille y su congregación de surrealistas "disidentes" -que más tarde incluiría a Antonin Artaud, Michel Leiris y Roger Caillois- se aproximan a la estética surrealista en términos de un materialismo histórico que evoca lo bajo y lo abyecto, con el fin de "inmediatamente crear sus propios valores para oponerlos a los 
valores establecidos" (Bataille, 1974: 290)33. Según la crítica de Bataille, el pensamiento bretoniano falla en su "revolución" ya que recurre a motivos idealistas como el acercamiento a lo más allá, lo absoluto y los valores etéreos (1974: 292, 300). Y es más, aun artistas y cineastas como Salvador Dalí y Luis Buñuel, ambos tan importantes para Lorca y otros españoles en su entendimiento del surrealismo, se encuentran dentro de estos debates.

En septiembre del año 1929, Documents era la primera revista en París que reprodujo las pinturas de Dalí, y según Dawn Ades, Dalí y los sujetos caídos, los relojes disueltos y los ojos seccionados de su obra se identificaban mejor con la estética más perversa y grotesca de Bataille; su Historia del ojo era una lectura que a Dalí le fascinaba y que le impactaba mucho (Ades, 1995a: 66-70). Sin embargo, por razones de publicidad y promoción artística, Dalí se sentía obligado a afiliarse oficialmente con Breton y su grupo, aunque Dalí mismo le decía a Lorca que iba "teniendo [sus] maneras al margen del surrealismo" (Gibson, 1999: 229) y aunque muchas de las imágenes de sus pinturas (como el excremento de El juego lúgubre, tan celebrado por Bataille) le repugnaban a Breton ${ }^{4}$. En este sentido, Gregory Stallings acierta en su análisis de la fuerza desestabilizadora de las pulsiones dionisíacas que se encuentran en la poesía, la pintura y la música jazz, concluyendo que el pensamiento de Bataille promueve una caída hacia una identidad inestable y que tal estética intenta subvertir la "arquitectura" de la tradición platónica occidental (2009: 17). Esta línea de aproximación al arte vanguardista, como en las obras de Dalí y Buñuel, reconoce y hace hincapié en los impulsos hacia la muerte, la representación de la angustia y la imposibilidad del cumplimiento del deseo, motivos que cobran suma importancia dentro del contexto hispánico.

La negación del control consciente - precisamente aquello con lo que varios de los surrealistas españoles, como Lorca, no estaban de acuerdo- fue revolucionaria sólo hasta el punto de ser irracional, pero no necesariamente porque estableciese una crítica directa o estructurada. En España, al igual que en otros países hispanos, la polémica del surrealismo nace debido al rechazo

\footnotetext{
${ }^{3}$ Para más información sobre la postura batailleana en cuanto al surrealismo, podríamos remitirnos a los artículos de Documents ("El lenguaje de las flores", "Materialismo", "Ojo", "Informe", "El juego lúgubre" y "El bajo materialismo y la gnosis").

${ }^{4}$ Por cuestiones de espacio, el presente trabajo no toma en cuenta las otras variadas postulaciones surrealistas de Dalí y Buñuel, ambos amigos de Lorca y muy influyentes en su concepción del surrealismo, la forma y lo informe. En cuestiones de la relación con Bataille, hay varias otras fuentes que vinculan el pensamiento daliniano y buñueliano con la estética del francés ya que participaron más directamente en el ambiente parisino de vanguardia. El curioso lector debería referirse a las obras de Dawn Ades aquí mencionadas junto con sus otros volúmenes sobre Dalí y el surrealismo. Agustín Sánchez Vidal también discute estas relaciones complicadas en su bien documentado Buñul, Lorca, Dali: El enigma sin fin (1988: 208-210, 217).
} 
explícito de la estética bretoniana y su enfoque en el automatismo y el subconsciente por parte de varios poetas hispanos designados como surrealistas 5 . La tendencia intelectual española proclama, en este sentido, una dependencia de las tradiciones propiamente españolas o hispanoamericanas, como el romanticismo, el modernismo y el arte deshumanizado o desinteresado tal cual lo concibió Ortega y Gasset ${ }^{6}$. No obstante, la mayoría de los hispanistas, como C.B. Morris, por ejemplo, tiende a trazar varias inclinaciones surrealistas que promoverían una lectura más bretoniana (o por lo menos más ortodoxa) del surrealismo en España. Bien es sabido que algunos de los poetas españoles sondearon el modelo bretoniano de creación artística (como en algunas de las obras de Vicente Aleixandre y Luis Cernuda, por ejemplo), aunque la gran mayoría de los poetas de la Generación del 27 recurren al uso de otros recursos estéticos como fuente de su producción poética. En su estudio Surrealism and Spain, Morris sigue las trayectorias de la estética en España y Francia con el fin de hacer una crónica del contacto entre el surrealismo español y el movimiento francés (1972: 8). Morris examina, además, la presencia de lo que Bataille llamaría la imagen subversiva (los sujetos deformados, la basura, el excremento, la descomposición agónica y las pesadillas), lo cual promovería una re-valoración del surrealismo en términos del "filósofo excremental", cuya revista Documents se había consolidado como un legítimo rival contra el surrealismo oficial (Morris, 1972: 111-59; Ades, 1995b: 78).

Quedaría, pues, reducida a un análisis superficial la negación por completo de la importancia de Breton en España, junto con la introducción de los escritos de Freud, que según Julio Huélamo Kosma y otros habían sido traducidos al español y que se leían y se discutían con frecuencia en la Residencia de Estudiantes en Madrid (1989: 59). Sin embargo, la crítica más reciente ha demostrado lo complicado que sigue siendo la concepción

${ }^{5}$ Aquí señalo solamente los principios claves del surrealismo y algunas de las preocupaciones centrales de la crítica, además de los puntos de desacuerdo entre Breton y Bataille. Una investigación exhaustiva del movimiento podría considerar a fondo los textos ya clásicos como The Surrealist Mode in Spanish Literature de Paul Ilie (1968); Surrealism and Spain de C.B. Morris (1972); Los poetas surrealistas españoles de Vittorio Bodini (1982); El surrealismo, editado por Víctor García de la Concha (1982) y The History of Surrealism de Maurice Nadeau (1989), junto con las más recientes contribuciones a la polémica del surrealismo español: Metal Butterflies and Poisonous Lights: The Langange of Surrealism in Lorca, Alberti, Cernuda, and Aleixandre de Derek Harris (1998); A Companion to Spanish Surrealism, editado por Robert Havard (2004) y Apocryphal Lorca: Translation, Parody, Kitsch de Jonathan Mayhew (2009).

${ }^{6}$ Según Octavio Paz, muchos de los motivos e imágenes surrealistas basados en la angustia, el vacío, lo grotesco, el erotismo y la transgresión tienen sus raíces en el romanticismo, aunque el escritor mexicano reconoce que la idea de un romanticismo propiamente español es problemática (1974: 57-58, 71, 115-122). 
de un "surrealismo español". Por su parte, Jonathan Mayhew sugiere que la noción del "surrealismo en España" nace por causa de poetas y críticos norteamericanos que entre 1950 y 1970 leyeron los textos de Lorca y otros y que "apócrifamente" designaron a estos escritores como "poetas surrealistas" (2009: 19-20). Estas calificaciones de "surrealista" ocurrieron, en muchos sentidos, antes de que se reconocieran las complicaciones centrales del movimiento presentadas por la crítica en las últimas décadas del siglo XX: la adherencia (o no) al automatismo, otros parámetros de la práctica "surrealista”, las divergencias dentro de los grupos surrealistas franceses y la negación del movimiento por parte de muchos poetas españoles de vanguardia. Aun en su demolición de la idea de un surrealismo español, Mayhew reconoce lo difícil que es separar a Lorca de los debates surrealistas, es decir, considerar fuera del contexto del surrealismo textos como Poemas en Prosa, Poeta en Nueva York, Viaje a la luna, Asi que pasen cinco años y El público-obras que en alguna u otra manera parecen rozar la estética francesa (2009: 19).

Asimismo Andrew Anderson y Derek Harris cuestionan la adherencia al surrealismo en los textos lorquianos frecuentemente calificados como surrealistas. Anderson sostiene que es más apropiado hablar de los escritos de Lorca en términos de vanguardismo, creacionismo, expresionismo o el "hecho poético" ya que concuerdan en muy pocos aspectos con el surrealismo bretoniano (1991: 156-159; 2004: 180-82). Tal vez es Harris quien más rompe con las conformidades críticas surrealistas al considerar el surrealismo más allá de los contextos bretonianos del automatismo y las manifestaciones del subconsciente. Harris examina la poesía surrealista española por su uso del lenguaje, sus motivos agresivos y las imágenes irracionales empleadas -elementos vistos como síntoma de una deshumanizada "poesía de crisis" (1998: 12-13). Dicho todo esto, se ve claramente que el surrealismo español (tal como la versión francesa) es una estética repleta de complejidades no sólo en las variaciones teóricas sino también en términos de adherencia y práctica. El pensamiento de Bataille que se elabora en este artículo provee una textura cultural adicional a un período de tendencias artísticas en constante flujo. El modelo surrealista batailleano añade, además, una contemplación del surrealismo que subraya de forma deliberada la angustia, la muerte y el deseo evidentes en la vanguardia española, preocupaciones materialistas que amplifican el campo de significados del término "surrealismo".

Lorca, sin ir más lejos, es explícito en su negación a la carencia de control del modelo bretoniano. En la correspondencia con su camarada Sebastià Gasch fechada en septiembre de 1928, el poeta granadino relata que su experimentación con nuevos estilos y formas exhibe "una tremenda ló- 
gica poética. No es surrealismo, ¡ojo!” (1996-1997: III, 1080). Lorca explica su resistencia al automatismo surrealista en su conferencia de 1928, "Imaginación, inspiración, evasión", cuando declara que "[e]l surrealismo emplea el sueño y su lógica para escapar. En el mundo de los sueños, el realísimo mundo de los sueños, se encuentran indudablemente normas poéticas de emoción verdadera. Pero esta evasión por medio del sueño o del subconsciente es, aunque muy pura, poco diáfana" (1996-1997: III, 104). Sin embargo, el año 1928 representa un momento clave en el desarrollo creativo y estético de Lorca y, tras la fuerte crítica de su Romancero gitano por parte de sus amigos Dalí y Buñuel, el granadino se siente impulsado a "amoldarse a las pautas del arte actual, es decir, [el] surrealismo" (Gibson, 1999: 233)7. En su estudio sobre Lorca y las vanguardias, Manuel Durán sugiere que, para Lorca, el uso de motivos vanguardistas era "el mejor antídoto contra el provincianismo, el andalucismo, [y] el gitanismo", y que "[ú] nicamente el surrealismo puro y la escritura automática hubiera podido satisfacer a Dalí y Buñuel" (1986: 767-68).

El resultado de aquella experimentación era, primero, la producción de los textos que han sido llamados los Poemas en prosa, escritos cortos publicados en revistas como L'Amic de les Arts y La Gaceta Literaria entre noviembre de 1927 y enero de $1929^{\circ}$. Como comprueban Ian Gibson y Agustín Sánchez Vidal, la desfavorable recepción de su Romancero gitano -obra acusada por ser anacrónica, tradicional, antigua y estereotipada- le era muy motivadora a Lorca (Gibson, 1985: 566-71; Sánchez Vidal, 1988: 177-82) ${ }^{9}$. Lo que es más, la producción en 1929 de la película surrealista Un chien andalou, la cual Lorca veía como otra crítica de su provincialismo (además de su sexualidad) (Gibson, 1985: 588; Sánchez Vidal, 1988: 208), le urge al poeta a unas producciones posteriores cada vez más atrevidas como Poeta en Nueva York y Viaje a la luna.

En vez de recurrir a los surrealistas bretonianos como precursores de su nuevo modo de pensamiento, Lorca llama la atención sobre los "hechos

\footnotetext{
${ }^{7}$ Más allá de la "crisis sentimental" provocada por la terminación de su relación amorosa con el escultor Emilio Aladrén, Lorca reconoce en 1928 la necesidad de empujar los límites estéticos en sus escritos. Andrew Anderson (1991) detalla los acontecimientos más importantes de ese año en su artículo "Lorca at the Crossroads".

${ }^{8}$ Los Poemas en prosa se publicaron por primera vez en edición suelta en 2000, a cargo de Andrew Anderson (Granada: La Veleta). El curioso lector podría remitirse a los estudios de Terence McMullan (1990) y Rebeca Sanmartín Bastida (2004) para más detalles sobre los Poemas en prosa.

${ }^{9}$ En Lorca-Dali: El amor que no pudo ser, Ian Gibson (1999) da un resumen detallado de la historia de las reacciones de Dalí y Buñuel ante la publicación de Romancero gitano. Véase, por ejemplo, las páginas 225-243.
} 
poéticos", movilizaciones poéticas de evasión que, según Anderson, van más allá de lo puramente metafórico, pero que no disturban la percepción de la realidad de una manera tan extensiva como proponía Dalí (1991: 156). Lorca elabora su concepción de los hechos poéticos como metáforas que no responden a la conexión lingüística analógica sino a los motivos que son "puros, inexplicables, a veces poco notados por estar en línea de poemas imaginativos" (1996-1997: III, 108). Asimismo, Lorca enuncia a "los nuevos valores de la poesía española: Larrea y Diego" para afirmar que "Juan Larrea y su discípulo Gerardo Diego construyen poemas a base de hechos poéticos encadenados, cada vez más limpios de imagen" (1996-1997: III, 106, 109). Esta "lógica poética" demuestra un estilo poético calculado y controlado, aunque también innovador y experimental. Mientras el automatismo manifiesta una crítica estética por medio de lo irracional, los poetas de la Generación del 27 buscan cada vez más una crítica artística por medio del lenguaje metafórico cuidadosamente y conscientemente articulado.

Incluso dentro de las vanguardias hispánicas hay tensiones parecidas a las que existen entre Breton y Bataille. Lorca, como muchos otros, reconoce a aquellos poetas que parecen servirle como modelo. Además de la referencias a Larrea de Lorca en la ya citada conferencia, Cernuda también postula que las ideas y poemas de Larrea fueron fundamentales en la formación surrealista de Lorca, Alberti y otros poetas de la Generación del 27 (1957: 194). Podríamos citar como ejemplos los escritos de Larrea que aparecieron en las revistas Grecia, Carmen y Favorables París Poema durante los años 19181926, y también su colección de poemas de 1926-1927 titulado Oscuro dominio. En muchos de los textos de Larrea de esta época se presenta un tono de angustia, pesimismo y crisis, y se representan imágenes del cuerpo decaído y descompuesto ${ }^{10}$. La postura de Larrea es distinta a la de Breton y Larrea dedica muchas páginas a refutar al líder del surrealismo. En su introducción a la revista Favorables París Poema, por ejemplo, Larrea propone el proyecto vanguardista de una manera que cuestiona las intenciones de la sublimación hacia una realidad más ideal, señalando que "[n]o existe la perfección como no existe la verdad ni la belleza y ésta menos que para nadie para el artista" (2003: 354). Varios años después, Larrea expande sus argumentos sobre las variaciones del surrealismo en su estudio El surrealismo entre viejo y nuevo mundo (1944). En esta obra Larrea reclama una "sub-poética" que se opone a las orientaciones bretonianas y que se manifiesta en obras surrealistas

${ }^{10}$ El lector interesado podría remitirse, más específicamente, a los poemas "Otoño" y "Diluvio", publicados en Grecia en 1919, y "Fervor" de Oscuro dominio, todos recopilados en Versión celeste (Larrea, 2003). 
hispánicas. La sub-poética, según Larrea, supone un rechazo de la luz, la belleza, las formas exaltadas, el yo sublimado y la profecía. Ésta enfatiza la descomposición corporal, la sombra, el yo degradado, el impulso hacia la muerte y la "ululación angustiosa de lo informe" (1944: 86, 92). Mientras algunas tendencias del surrealismo se aferran al dogma de la "supervisión" y del entendimiento del "más allá", Larrea examina cómo los poetas surrealistas hispanos, Neruda y Lorca entre ellos, de-subliman cualquier discurso enaltecedor (1944: 88) ${ }^{11}$.

En el análisis formativo de la relación entre Lorca y lo informe, podemos señalar que dentro de las estéticas vanguardistas de los años 20 Lorca constantemente renueva formas artísticas de la tradición, como la del romancero, el cancionero, la aleluya, el retablillo y las coplas de hechura jonda o flamenca. Sin embargo, el viaje a Nueva York en 1929 ofreció al poeta granadino un nuevo ambiente socio-intelectual idóneo para el desarrollo de su estética vanguardista y expresiones creativas. Críticos lorquianos como Derek Harris, Christopher Maurer y Antonio Monegal están de acuerdo con que la estancia de Lorca en Nueva York supone un momento decisivo en la evolución de la poética lorquiana, puesto que es entonces cuando Lorca se dedica explícitamente a explorar con sus propias palabras e imágenes la estética vanguardista, entre las que cabe destacar las representaciones teatrales "imposibles" y los temas cada vez más intrépidos como en el guión Viaje a la luna (Harris, 1998: 83-87; Maurer, 1998: xv-xviii; Monegal, 2000: 16-19). El corpus poético que nace en este período, Poeta en Nueva York, articula una elaborada ruptura con los estilos, temas y formas poéticas antes utilizados por Lorca. Mientras Lorca emplea símbolos irracionales y metáforas a veces imposibles de restaurar, su uso es sutil y consciente, situándolo en los márgenes del automatismo surrealista ${ }^{12}$. La estructura ideológica en la poesía lorquiana busca criticar regímenes de dominación y discursos hegemónicos dentro de la sociedad, la religión y la economía. De una manera más solidaria que en sus escritos anteriores, Poeta en Nueva York se compromete con los seres marginados y valores radicales. La crítica social y estética, junto con la angustia del yo lírico y el deseo de expresar su propia subjetividad, se manifiesta en la vacilación entre diferentes formas discursivas y artísticas que

${ }^{11}$ Para más información sobre el papel de Larrea en el desarrollo del surrealismo español, véase mi artículo "Spanish Surrealism's absent father: The Sub-Realist poetry and poetics of Juan Larrea" en Bulletin of Spanish Studies (2012).

${ }^{12}$ En su estudio sobre la "deshumanización" de Poeta en Nueva York, Neil C. McKinlay elabora los temas de la interpretación, el distanciamiento, la alienación y la impenetrabilidad poética (2001: 159-62). 
Lorca maneja de una manera intensiva durante esta época.

Es dentro de esta estructura ideológica, claramente subrayada por las nuevas preocupaciones temáticas y dilucidada en originales estrategias narrativas, donde el análisis batailleano de lo informe, de la inversión del universo, se funde en armonía con la lógica poética lorquiana que pretende criticar y fragmentar las estructuras sociales y artísticas de su época. No obstante, mientras el deseo de subvertir la hegemonía dominante es común tanto en Lorca como en Bataille, el pensamiento batailleano se dirige a la destrucción sublime. En contraste, la obra de Lorca muestra una profunda tensión entre lo informe, como crítica y escándalo, y lo informe como un vacío que elabora el lamento de la pérdida, recurriendo a la nostalgia por un momento pretérito a la pérdida ${ }^{13}$. El sujeto estético viene a ser, para Lorca, el medio por el cual se articula el vacío como topos en el que se lamentan los surgimientos de lo informe. Estos espacios de lo informe en Poeta en Nueva York, junto con los diversos vacíos y huecos, son elementos simbólicos de una vaciedad y desesperanza general, de lamento y de pérdida -movilizaciones artísticas que encuentran sus raíces en las visiones pesimistas barrocas y después en las figuras distorsionadas goyescas-. Ya sea por la aniquilación pura y radical de la forma como en Bataille, o bien por la más compleja y multifacética naturaleza de lo informe en Lorca, lo que emerge en su poética es una estética que desafía los límites de la representación y la expresión.

En Poeta en Nueva York, el lector se enfrenta a imágenes de la muerte, formas corporales disueltas y líquidos como la sangre y el vómito. Pero lo informe no sólo se representa por medio de la materia corporal que Lorca articula con el fin de establecer una dialéctica con lo sublime, sino que es, al mismo tiempo, la coyuntura de una denuncia calculada y precisa. En la cisura de ambos discursos se encuentra el lugar agónico que ocupa el deseo y la precisa imposibilidad de poder expresarlo dentro de la diégesis discursiva. Mientras que "lo informe en Lorca" busca reconocer las tensiones y contradicciones en la articulación del deseo y la identidad, también critica, vuelve informe, y deconstruye (por medio de la enunciación poética) las pautas hegemónicas y formas narrativas que delimitan la expresión del sujeto poético. El yo, fragmentado y mutilado, se vuelve informe al mismo tiempo que intenta utilizar la forma artística para cuestionar los sistemas de poder que marginan al otro. Sin embargo, esta destrucción de valores, que

${ }^{13}$ Según lo ha mostrado Paul Julian Smith, la colección neoyorquina de Lorca está llena de contradicciones o "ambivalencias" de este tipo. Para Smith, las dicotomías poéticas relacionadas con la (homo)sexualidad, la raza y la modernidad constituyen proyecciones y contradicciones del poeta mismo (2000: 170-75). 
señala nuevas formas de relacionarse con el ser y el arte, no supone ni la sublimación de la belleza surrealista ni la falta de control poético que sugiere el automatismo.

A partir de los primeros versos de Poeta en Nueva York los espacios y materias que evocan lo informe son evidentes cuando el yo lírico es "asesinado por el cielo" y atrapado "entre las formas que van hacia la sierpe / y las formas que buscan el cristal" (1996-1997: I, 511) ${ }^{14}$. Es dentro y desde estos espacios vacíos, en relación con las formas susceptibles a la metamorfosis y la maleabilidad, que la voz poética intenta articular su expresión. La lógica de lo informe en este poemario exhibe una interrogación radical de las variaciones modernistas de la subjetividad al presentar el yo como un ente caído y banal. Sin aferrarse a una aspiración por el yo sublime, los personajes de la colección están destrozados y descoyuntados. De acuerdo con el análisis de Martha J. Nandorfy, la visión apocalíptica de la cuidad se desdobla en un yo poético decaído. Nandorfy sugiere que el sujeto fragmentado "situates himself within a tenuous flux of forms; but he is, at the same time, distant, jostled, and bewildered in the midst of a phantasmal crowd" (2003: 36). Esta representación del organismo cuestiona las nociones de la proporción, la simetría y la belleza.

En los poemas lorquianos de esta época, el sujeto poético se encuentra constantemente atrapado en espacios nihilistas donde la identidad es erradicada por completo y hecha informe con el fin de reconstituirse en la forma del otro. Estos textos son a la vez imágenes de la aniquilación del ambiente exterior y también reflejos de las fragmentaciones interiores del sujeto. El primer poema de la colección, "Vuelta de paseo", prefigura mucha de la angustia y protesta que se elabora a lo largo del poemario mientras llama la atención a la fuerza aniquiladora del cielo que destruye la naturaleza, el deseo y la subjetividad. Aquí la voz lírica clama contra la muerte y las mutilaciones provocadas por lo que Lorca denomina "arquitectura extrahumana y ritmo furioso. Geometría y angustia” (1996-1997: III, 164):

Asesinado por el cielo.

Entre las formas que van hacia la sierpe

y las formas que buscan el cristal,

dejaré crecer mis cabellos.

${ }^{14}$ Es notable recordar que los primeros versos de Residencia en la tierra de Neruda también elaboran un espacio de tensiones materiales, "Como cenizas, como mares poblándose, / sumergida lentitud, en lo informe” (1999-2002: I, 257). 
Con el árbol de muñones que no canta

y el niño con el blanco rostro de huevo.

Con los animalitos de cabeza rota

y el agua harapienta de los pies secos.

Con todo lo que tiene cansancio sordomudo

y mariposa ahogada en el tintero.

Tropezando con mi rostro distinto de cada día.

¡Asesinado por el cielo!

(1996-1997: III, 511).

Estar asesinado por el cielo le recuerda al lector el sol icario que ciega y mutila al que intenta aproximarse a él, subvirtiendo la noción del cielo como una fuente de belleza al vincularlo con la muerte ${ }^{15}$. Esta inversión de motivos continúa en los versos dos y tres, los cuales indican un espacio vago de formas en constante flujo, entre las formas bajas de la sierpe y las formas altas del cristal.

Christopher Maurer sugiere que estos espacios de vacío constituyen una parte esencial de la representación de la monstruosidad del ambiente neoyorquino cuando señala que el nihilismo lorquiano "gives rise to one of the most frequent and most untranslatable images in the book: the hueco: void or hollow, space or emptied space", concluyendo que la atmósfera en Nueva York está saturada de huecos y vacíos que en la poética lorquiana simulan sujetos destrozados e informes (1998: xxix). A través de la repetición anafórica de ambas construcciones "con" y "y el", el yo poético de "Vuelta de paseo" se identifica con otras figuras (como el árbol, el niño, los animales rotos, el agua, los sordomudos y la mariposa) que tampoco pueden adquirir el objeto de su deseo. Estos sujetos se muestran tropezando y cayéndose mientras añoran el cumplimiento de su ser: el árbol amputado no puede crecer ni cumplir su destino debido a que se ha cortado; la identidad del niño está borrada y su cara se ve sólo como un espacio blanco y sin expresión; el agua con pies secos no contiene ni la característica más esencial de su existencia (la humedad); los sordomudos no pueden comunicarse debido a su incapacidad para poder articular el lenguaje por medio del habla; y la palabra se

${ }^{15}$ Bataille trata más la ceguera provocada por un sol agresivo en su novela Historia del ojo (1928) y en su artículo "Sol podrido" de Documents (1930, N 3). 
ahoga como la mariposa en el tintero y así la expresión misma se aniquila por falta del poder escribir. A nivel meta-poético, el texto sugiere no sólo la muerte del yo y las dificultades asociadas con la expresión poética, sino también demuestra una caída de la iconografía romántica que busca lo ideal. De acuerdo con esta identificación, Ángel Sahuquillo propone que todos los sujetos del poema "comparten el mismo destino: ser creados con cierta forma e instinto para, después, ser acusados, condenados y sacrificados por ser como son" (1990: 500). Por causa del asesinato del cielo en "Vuelta de paseo", la voz poética (o el poeta mismo) es semejante a las otras figuras que nombra puesto que ninguno puede encontrar una existencia estable dentro del ambiente metropolitano ${ }^{16}$.

El yo caído y fragmentado que persiste en "Vuelta de paseo" se personifica de manera visual en el dibujo "Autorretrato en Nueva York", donde se vislumbra tan sólo la cabeza y las manos del poeta. Este ser mutilado y reducido hace eco de los argumentos batailleanos de Rosalind Krauss. Esta crítica ilustra la decadencia hacia la horizontalidad y vulgaridad del sujeto que se encuentra en este tipo de ambiente represivo, cuando señala que "[t]he body then de-solidifies with his thoughts, the individual breaks the boundaries of his skin and occupies the other side of his senses... They are [subjects] falling, falling from the vertical into the horizontal" (1998: 155-56). En el caso de los poemas y dibujos de Lorca en Nueva York, el yo poético sucumbe en un estado de fragmentación y de vacío entre la forma y lo amorfo. La fragmentación de la forma y del sujeto poético no solamente contiene una crítica estética y social, sino que también ofrece un nuevo espacio narrativo que invita a la creación y reflexión poética. En este sentido, quebrar la forma violentamente y dar forma son partes igualmente importantes del acto estético vanguardista. Precisamente, al renovar la expresión por medio de la transgresión, Lorca supera los límites del nihilismo batailleano. Para Lorca el manifiesto estético no es solamente aquel que da forma. La forma es clave, sí, pero igualmente es esencial cuestionar y quebrar las convenciones que regulan la expresión a fin de abrir un nuevo espacio para la creación artística. En tanto que la noción de Bataille de lo informe propone la aniquilación absoluta de la forma, Lorca emplea los espacios del vacío para demostrar la esencia conflictiva ("ambivalente") de la individualidad y para subyugar la angustia del sujeto poético.

Lo informe, lo amorfo, viene a glosar, ante la mirada curiosa del lector,

\footnotetext{
${ }^{16}$ Nandorfy sugiere que la pérdida del yo, junto con su identificación con los otros marginados, señala una evolución ética en la obra de Lorca: "Loss of self amounts to introjecting otherness and becoming empathetically vulnerable to the needs and desires of others" (2003: 270).
} 
los espacios del deseo humano, los huecos de naturaleza puramente nihilista heredados de la teología barroca y arrastrados por la imagen del desengaño. Así el poeta granadino expande los límites de lo informe según los han detallado Krauss y Bois (1997: 26-40) al incluir en el diálogo los espacios del deseo, siendo precisamente en estos márgenes donde se examina la angustia del yo lírico y la necesidad de una nueva expresión artística. Aun así, y junto con la mirada del sujeto que en la constante búsqueda de su identidad permanece inmóvil como las letras de un poema, el poeta se presenta solo frente al vacío. Lo desafía en su propia ausencia. Lejos de toda diégesis racional, el poeta confronta el discurso ideológico con una imagen capaz de manifestarse más allá de los propios deseos del subconsciente. Con ella, el surrealismo llega a su máximo esplendor poético.

Mientras la contemplación se densifica sobre los espacios informes del deseo en Poeta en Nueva York, al acercarnos al "Nocturno del hueco"17 los huecos y vacíos connotan sentimientos contradictorios y ambivalentes que afirman la complejidad del deseo y la falta de inteligibilidad del discurso surrealista lorquiano. El hueco señala un tono de lamento y angustia mientras también presenta una contemplación sobre la búsqueda sombría del objeto del deseo. El "Nocturno" comienza aludiendo a la ausencia que causa el vacío, "Para ver que todo se ha ido, / para ver los huecos y los vestidos" (1996-1997: I, 547). El yo lírico reconoce la tensión entre los huecos heredados por el incumplimiento del deseo y la satisfacción otorgada al obtener el objeto deseado. Como en otros poemas de la colección en los que el sujeto poético no consigue lo que busca, el yo lírico aquí se atiene a su deseo. Con una actitud de desencanto propio del barroco, el yo detalla cómo los seres que buscan los espacios de la sierpe quedan atrapados en un "duro cristal definitivo" (1996-1997: I, 547). Como en "Vuelta de paseo", el sujeto del "Nocturno" se visualiza como ente en un proceso truncado, sin poder llegar a su meta, su plenitud. El "Nocturno" lamenta el hueco como un espacio de la soledad mientras simultáneamente celebra los "huecos puros" del pasado que se memorizan. Aquí, el yo lírico establece cada vez más la complejidad del hueco; primeramente como un espacio de pérdida y duelo, pero también como un recuerdo nostálgico, casi melancólico, que se considera especie

${ }^{17}$ Del poema "Nocturno del hueco" se publicaron varias versiones (la de Caballo verde para la poesía [octubre de 1935], la de la edición Norton [mayo de 1940] y la de la edición Séneca [junio de 1940]). Para un breve resumen de las diferencias de estos textos, véase la nota de Miguel GarcíaPosada en su edición de las Obras completas de García Lorca (1996-1997: I, 947) y para una historia más extensa el lector podría referirse al estudio de Daniel Eisenberg (1976). Aquí yo sigo la versión de Caballo verde, la única que se imprimió en la vida del autor y la que se reproduce en las Obras completas compiladas por García-Posada. 
pura o ideal del deseo cumplido. En este sentido, Lorca emplea la ausencia del cumplimiento para explorar las posibilidades y complejidades de la pérdida, utilizando el idealismo y la forma para articular la ausencia del espacio ambiguo, ambivalente y contradictorio del deseo.

El primero de los dos apartados del "Nocturno" se centra en la relación entre un yo lírico y un otro, llamado "amor mío". El yo enfatiza la soledad repitiendo el verso "todo se ha ido" siete veces a lo largo de esta primera parte. Puesto que todo se ha perdido, lo que queda son los huecos, los espacios del vacío. De forma análoga, Lorca emplea otros objetos que en algún sentido necesitan de otra entidad para estar enteros: la ropa (que necesita un cuerpo), el guante (que necesita una mano) y el pulmón (que necesita el aire). Sin embargo, hay momentos de satisfacción, siempre entrelazados con el dolor, que sirven para revelar el sentido ambivalente del deseo y del hueco:

Dentro de ti, amor mío, por tu carne, ¡qué silencio de trenes boca arriba! ¡cuánto brazo de momia florecido! ¡qué cielo sin salida, amor, qué cielo!

Es la piedra en el agua y es la voz de la brisa bordes de amor que escapan de su tronco sangrante.

Basta tocar el pulso de nuestro amor presente para que broten flores sobre los otros niños (1996-1997: I, 547-548).

Estas dos estrofas ilustran la textura híbrida del vacío. Al tener contacto físico y erótico con el otro existe un silencio que podría señalar simultáneamente a la soledad y al reposo. En el momento de estar envuelto por el otro, como "la piedra en el agua" o como "la voz en la brisa", la satisfacción se aproxima. No obstante, el discurso permanece plagado de vocablos que evocan un sentido delimitado o sombrío: "brazo de momia florecido" y "cielo sin salida". La excitación es evidente cuando los bordes del amor se escapan del tronco sangrante, mientras el impulso amoroso se extiende hacia otros; aun así, la fuente de la reflexión sobre este amor (junto con la necesidad de satisfacer el deseo) emana desde una perspectiva de angustia y dolor, desde el "tronco sangrante", insinuando que el amor no se domina por la belleza y la realización del deseo.

Estos versos indican que la plenitud se puede obtener en cierto sentido por medio del contacto con el otro, pero que el deseo es negociado no sólo 
por el placer sino también por el lamento y la pérdida. Entre las formas que buscan lo estable y las "formas concretas que buscan su vacío" dentro del ambiente poético -entre el lamento y la plenitud- el yo poético contempla los "huecos puros, por mí, por ti" (1996-1997: I, 548). Los huecos puros son espacios en los que se generan actitudes de inocencia o renacimiento, pero también espacios vacíos dentro de los cuales la expresión puede madurar y florecer. Lorca emplea este contraste entre el vacío y la plenitud para acentuar la tensión que existe entre el deseo y la pérdida. En cada momento del discurso poético el yo lírico lamenta y celebra los espacios informes de los vacíos y huecos. Esta postura ambivalente hacia el vacío señala a un complejo y productivo mecanismo de producción poética donde podemos observar las estructuras conflictivas del deseo en la lírica amorosa lorquiana.

Sin embargo, la última estrofa de la primera sección del nocturno anticipa un cambio en el tono que dominará la segunda parte del poema: un tono de angustia intensificada y falta de esperanza. El yo poético reconoce que la pérdida del objeto del deseo es inevitable:

Para ver que todo se ha ido jamor inexpugnable, amor huido!

No, no me des tu hueco, ¡que ya va por el aire el mío! ¡Ay de ti, ay de mí, de la brisa! Para ver que todo se ha ido (1996-1997: I, 548).

Puesto que todo ha desaparecido, las aspiraciones del yo poético no pueden realizarse y éste se resigna a lamentar su pérdida. No podrá satisfacer el deseo del otro dado que su propio hueco se desvanece en el aire. Mientras el poema comienza demostrando las características conflictivas del hueco y el deseo en términos generales, esta última estrofa orienta el enfoque temático del segundo apartado: el hueco "mío" que flota en el aire.

La segunda y última sección del poema comienza con un verso de una sola palabra: "Yo". Este verso se repite cinco veces a lo largo de esta sección y hace hincapié en el sentido de la angustia íntima y personal del yo poético. El deseo del yo no se satisface porque el vacío informe del hueco se queda sin llenarse; el deseo queda en ceniza y "traspasado con las axilas rotas" como una "piel seca de uva neutra y amianto de madrugada" (1996-1997: I, 549). La soledad no aniquila el deseo ya que el yo lírico queda angustiado, negado cualquier tipo de renacimiento o reconocimiento en el otro. Los últimos 
versos del poema indican el estado desesperado que provoca el ambiente de la ciudad vacía:

Yo.

Mi hueco sin ti, ciudad, sin tus muertos que comen.

Ecuestre por mi vida definitivamente anclada.

Yo.

No hay siglo nuevo ni luz reciente.

Sólo un caballo azul y una madrugada

(1996-1997: I, 549).

La palabra final "madrugada" recuerda el poema "Aurora" del mismo poemario en el que el hablante considera que el nuevo día sólo trae un nuevo comienzo a una muerte permanente y no una exhortación del renacimiento o belleza pastoril. El nocturno lorquiano se acerca a lo que está en juego con la articulación del deseo y las posibilidades (o imposibilidades) de realizarlo. Acierta Estrella de Diego al señalar que en la obra de Lorca, "el deseo se escapa de las páginas, se desliza entre las teorías: no puede ser atrapado, expresado" (1998: 195). O como Maurer afirmó en su momento, "the object of desire is never specified... for there is nothing to hold fast to, nothing but the poem itself, and the lingering ache of desire" (2002: xxxviii). Sin embargo, los huecos y vacíos del poema de Lorca son los espacios de dolor y soledad, aunque también conforman aquellos espacios necesarios para la creación poética, vacíos puros en búsqueda de su expresión. La voz poética demuestra que los vacíos y las ausencias son mucho más que huecos materiales o físicos. Son, en cambio, espacios de contemplación y de posible articulación del deseo.

Desde sus diferentes perspectivas, Lorca y Bataille crean textos vanguardistas que dialogan sobre lo informe a fin de examinar la conflictiva naturaleza del deseo. Mientras para Lorca el hueco sirve para investigar el deseo y la pérdida, Bataille celebra plenamente el vacío como una sustitución del objeto deseado que ayuda a superar la soledad. En un apartado de su poema en prosa "El techo del templo", Bataille elabora la relación entre el vacío y el deseo:

Al mismo tiempo, el amor me enardecía. Yo estaba limitado por las palabras. Me consumí de amor en el vacío, como en presencia de una mujer deseable y desvestida, pero inaccesible. Sin poder tan siquiera expresar un 
deseo... Al mirar fijamente el vacío ante mí, una súbita imantación violenta, excesiva, me unió a ese vacío. Veía ese vacío y no veía nada, pero él, el vacío, me abrazaba (1982: 56).

Aquí el vacío se acerca al sujeto poético y viene a ser el agente del abrazo. Esta mirada del vacío difiere de la preocupación lorquiana en el "Nocturno", lo cual indica mucho sobre la esencia y fluidez del deseo. El yo poético batailleano queda limitado por el lenguaje y no puede expresarse. El vacío, entonces, sirve como un espacio de contemplación de la inhabilidad de expresar la presencia constante del deseo.

A modo de conclusión, podemos señalar que en ambos casos los huecos informes provocan y señalan a una toma de conciencia: la necesidad de la expresión, captada por un instinto surrealista que encierra la angustia del dolor y la nostalgia de llenar o crear un discurso poético. Los huecos para Lorca llegan a ser algunos de los más ricos y complejos motivos de su obra poética: son espacios de deseo, ímpetu, espacios necesarios para la expresión, la fuente de una profunda contemplación de la identidad humana y el vacío que señala la necesidad del contacto con el otro. Estos huecos muestran un claro deseo por el placer físico, pero también reconocen el lamento, la pérdida y la angustia. Como escribe Lorca en "Navidad en el Hudson", otro poema de Poeta en Nueva York, "Lo que importa es esto: hueco. Mundo solo. Desembocadura" (1996-1997: I, 531). Y mientras el hueco representa un espacio informe del deseo que busca realizarse, éste también refleja un lugar abierto a la expresión artística. A pesar de que Lorca no construye un discurso tan violento en tono y actitud como el de Bataille (le interesa más la expresión de la ausencia que la representación de la violencia presente), ambos comparten la carencia de forma del vacío para postular una transgresión surrealista de variantes modernas del ser y la expresión. El sujeto lírico desea algo que está más allá del lenguaje, por debajo de la superficie de la convención. Para Bataille, el resultado viene en sus escritos posteriores que discuten una renovación de lo sagrado como parte de una "economía general". Para Lorca, lo que trasciende es la infinita búsqueda de posibilidades capaces de promulgar la expresión del deseo, posibilidades que el poeta sigue explorando luego en obras surrealistas cada vez más transgresoras como Viaje a la luna, El público y Así que pasen cinco años.

Nuestro análisis sobre Lorca, Bataille y las variantes del surrealismo hispánico ha tenido como propósito presentar nuevos modelos analíticos capaces de sumar más riqueza cultural sobre el corpus poético del poeta granadino, subrayando, ante todo, la forma en que el pensamiento de Bataille aporta 
nueva luz al entendimiento de las estéticas vanguardistas y a la expresión lorquiana en particular. A principios del siglo XXI, y cuando los debates políticos pugnan de nuevo por ubicar el cuerpo perdido de Lorca, nosotros hemos intentado, desde estas breves páginas de reflexión, encontrar al poeta en su propio corpus poético para mostrar la trascendencia latente de su singular legado. Aunque tal vez pueda haber claras razones capaces de teñir el debate sobre el paradero del último paseo del poeta andaluz, también es posible que Lorca, al igual que su poesía y su legado literario, pertenezca para siempre a la tierra, a los fondos oscuros del vacío, atrapado permanentemente en la fosa de los otros. Y así se nos presenta que, mientras intentamos "dar forma" al enigma del cuerpo perdido, el silencio de la fosa invita al abandono de la lógica cartesiana y la presencia permanente de lo informe y del deseo. Contradicciones de la vida, lógica de la poesía, legado de Federico García Lorca.

\section{REFERENCIAS}

Ades, Dawn. (1995a). Dali. London: Thames and Hudson.

(1995b). Internationalism and Eclecticism: Surrealism and the avant-garde in painting and film 1920-1930. En Helen Graham y Jo Labanyi (ed), Spanish cultural studies: An introduction (pp. 71-79). Oxford: Oxford University Press.

Ades, Dawn, y Simon Baker. (2006). Undercover Surrealism: Georges Bataille and Documents. Cambridge: MIT Press.

Anderson, Andrew A. (1991). Lorca at the Crossroads: 'Imaginación, inspiración, evasión' and the 'novísimas estéticas'. Anales de la Literatura Española Contemporánea, 16, 149-73.

. (2004). García Lorca’s Poemas en prosa and Poeta en Nueva York: Dalí, Gasch, Surrealism, and the Avant-garde. En Robert Havard (ed), A companion to Spanish Surrealism (pp. 163-82). Woodbridge, UK: Tamesis.

Bataille, Georges. (1974). El 'viejo topo' y el prefijo sur en las palabras surhomme y superrealiste. En Obras escogidas (pp. 289-308). Trad. Joaquín Jordá. Barcelona: Barral. (1982). Lo Arcangélico y otros poemas. Trad. Pilar Ruiz Va. Intro. Bernard Nöel. Madrid: Visor. . (2003). La conjuración sagrada. Ensayos 1929-1939. Trad. e intro. Silvio Mattoni. Buenos Aires: Adriana Hidalgo. 
Breton, André. (1969). Manifiestos del surrealismo. Trad. Andrés Bosch. Madrid: Guadarrama.

Cernuda, Luis. (1957). Estudios sobre poesía española contemporánea. Madrid: Guadarrama.

Diego, Estrella de. (1998). Dar algo que uno no tiene. Revista de Occidente, 211, 195-202.

Durán, Manuel. (1986). Lorca y las vanguardias. Hispania, 69, 4, 764-770. Eisenberg, Daniel. (1976). Poeta en Nueva York: Historia y problemas de un texto. Ariel: Barcelona.

Foster, Hal. (2000). Compulsive beauty. Cambridge: MIT Press.

García Lorca, Federico. (1996-1997). Obras completas. Ed. Miguel GarcíaPosada, 4 vols. Barcelona: Galaxia Gutenberg-Círculo de Lectores. La Veleta.

Gibson, Ian. 1985. Federico García Lorca. 1. De Fuente Vaqueros a Nueva York (1898-1929). Barcelona: Grijalbo. DeBolsillo.

(1999). Lorca-Dalí: El amor que no pudo ser. Barcelona:

Harris, Derek. (1998). Metal butterflies and poisonous lights: The language of Surrealism in Lorca, Alberti, Cernuda, and Aleixandre. Scotland, UK: La Sirena.

Huélamo Kosma, Julio. (1989). La influencia de Freud en el teatro de García Lorca. Boletín de la Fundación Federico García Lorca, 3, 6, 59-83. Krauss, Rosalind E. (1998). The optical unconscious. Cambridge: MIT Press. Krauss, Rosalind E. e Yve-Alain Bois. (1997). Formless: A user's guide. New York: Zone Books.

Larrea, Juan. (1944). El surrealismo entre viejo y nuevo mundo. México D.F.: Cuadernos Americanos. (2003). Versión celeste. Ed. Miguel Nieto. Madrid: Cátedra.

Maurer, Christopher. (1998). Introduction. En Poet in New York: A bilingual edition (pp. xiii-xxxv). Por Federico García Lorca. Ed. Christopher Maurer. Trad. Greg Simon y Steven F. White. New York: Noonday Press . (2002). Introduction. En Collected Poems: Revised bilingual edition (pp. xi-lxiv). Por Federico García Lorca. Ed. Christopher Maurer. Trad. Christopher Maurer, Steven F. White y Greg Simon. New York: Farrar, Straus and Giroux.

Mayhew, Jonathan. (2009). Apocryphal Lorca: Translation, parody, kitsch. Chicago: University of Chicago Press.

McKinlay, Neil C. (2001). The dehumanisation of Poeta en Nueva York. 
Tesserae: Journal of Iberian and Latin American Studies, 7, 2, 157-71.

McMullan, Terence. (1990). Federico García Lorca’s Santa Lucía y San Lázaro and the aesthetics of transition. BHS LXVII, 1-20.

Monegal, Antonio. (2000). Introducción. En El público / El sueño de la vida (pp. 7-42). Por Federico García Lorca. Alianza: Madrid.

Moreno Villa, José. (1998). Poesías completas. Ed. Juan Pérez de Ayala. México D.F.: El Colegio de México. (2001). Temas de arte: Selección de escritos periodísticos sobre pintura, escultura, arquitectura y música (1916-1954). Ed. e intro. Humberto Huergo Cardoso. Valencia: Pre-Textos.

Morris, C.B. (1972). Surrealism and Spain (1920-1936). London: Cambridge University Press.

Nandorfy, Martha J. (2003). The poetics of Apocalypse: Federico Garcia Lorca's Poet in New York. Lewisburg, PA: Bucknell University Press.

Neruda, Pablo. (1999-2002). Obras completas. Ed. Hernán Loyola, 5 vols. Barcelona: Galaxia Gutenberg-Círculo de Lectores.

Paz, Octavio. (1974). Los hijos del limo: Del romanticismo a la vanguardia. Barcelona: Seix Barral.

Richter, David F. (2012). Spanish Surrealism's absent father: The SubRealist poetry and poetics of Juan Larrea. Bulletin of Spanish Studies, 89, 5, 751-68.

Rodríguez, Juan Carlos. (2000). Lorca: Temas y variaciones en torno a la conciencia trágica (El nombrar en el soneto a Ciria, la negatividad del Diván y la manzana de Newton). En Federico García Lorca, clásico moderno (1898-1998): Congreso internacional (pp. 158-76). Ed. Andrés Soria Olmedo, María José Sánchez Montes y Juan Varo Zafra. Granada: Diputación de Granada.

Sahuquillo, Ángel. (1990). El asesinato de 'Vuelta de paseo' de Federico García Lorca. En Ensayos de literatura europea e hispanoamericana (pp. 493-504). Ed. Félix Menchacatorre. San Sebastián: Universidad del País Vasco.

Sánchez Vidal, Agustín. (1988). Buñuel, Lorca, Dali: El enigma sin fin. Barcelona: Planeta.

Sanmartín Bastida, Rebeca. (2004). De Dalí a Lorca: El poema en prosa surrealista. Forma Breve: Revista de Literatura, 2, 81-103.

Smith, Paul Julian. (2000). New York, New York: Lorca's double vision. Tesserae: Journal of Iberian and Latin American Studies, 6, 2, 169-80.

Stallings, Gregory C. (2009). Jazz y literatura. Valencia: Tirant lo Blanch. 